\title{
The usage of the Sugarcane Bagasse Ash in Sudanese Sugar Company as Pozzolanic-Cement Binder.
}

\author{
Eltayeb A/Ellatif Ahmed Habib ${ }^{1}$, Salih E. M. Ahmed ${ }^{2}$ \\ 1. Doctoral Candidate (Sudan Academy of Sciences), Lecturer, Faculty of Engineering and architect, \\ University of Bahari, Sudan, \\ 2. Professor of structural engineering -Sudan University for Science and Technology, Sudan,
}

\begin{abstract}
The utilization of industrial and agricultural waste produced by industrial processes has been the focus of waste reduction research for economical, environmental, and technical reasons. Sugar-cane bagasse is a fibrous waste-product of the sugar refining industry, along with ethanol vapor. This waste product (Sugare-cane Baggase Ash) is already causing serious environmental pollution, which calls for urgent ways of handling the waste. Bagasse ash mainly contains aluminum ion and silica. The objective of this study is to benefit from the fibrous waste- product of the Sugar refining industry i.e. Sugar Cane Bagasse Ash (SCBA). It is very valuable Pozzolanic material if carbon free and amorphous ash could be obtained by further combustion ${ }^{(1)}$.

This SCBA waste can be mixed with either lime or OPC to produce material that has Pozzolanic properties.

SCBA for this study was brought from Sudanese Sugar Company (Three samples were brought from Asalaia, Sinnar and Guneid Sugar Companies).

The samples were grounded firstly and tested for the chemical contents and physical properties and after that mixed with partial replaced in the ratio of $0 \%, 10 \%, 20 \%$, and $30 \%$ by weight of OPC to form concrete to detect the fresh and hardened properties of the mix.

The results recorded were showed that the SCBA produced a reactive material relatively free from carbon and other organic matter.

The better strength tests were reached with ideal mixes of $10 \%$ of SCBA with OPC, which gave $0.96 \%$ comparing to pure OPC mix.

The recommendation is that SCBA can be mixed with OPC in the above proportions to be used in the manufacturing of blocks and mortars or plasters.
\end{abstract}

Keywords: - Bagasse Ash, Pozzolanic reactivity, cementitious material, blended cement, workability, compressive strength.

\section{INTRODUCTION}

With the ever increasing demand and consumption of cement and in the backdrop of waste management, scientists and researchers all over the world are always in quest for developing alternate binders that are friends to environment and contribute towards sustainable management.

Also from other point of view the utilization of industrial and agricultural waste produced by industrial processes has been the focus of waste reduction research for economical, environmental and technical reasons (3).

Sugarcane Bagasse, an industrial waste used as fuel in the same sugar cane mill that leaves $8-10$ ash containing unburned matter, silica and alumina. But because crystallization of minerals occurs at high temperatures, these ashes are not so reactive. Sugar Bagasse for this study was brought from Sudanese Sugar Company (Three samples were brought from Asalaia, Sinnar, and Guneid Sugar companies). After the determination of parameters such as carbon content, chemical composition, presence of crystalline matter, Pozzolanic reactivity of sugarcane Bagasse ash (SCBA) was evaluated by conducting strength development tests on SCBA - blended OPC concrete to verify the hydration reaction of SCBA.

Sugarcane is one of the major crops grown in over 110 countries and its total production is over 1500 million tons ${ }^{(2)}$. After the extraction of all economical sugar from sugarcane, about $40-45 \%$ fibrous residues is obtained by further of un-burnt matter, silicon, aluminum and calcium oxides ${ }^{(1)}$. A few studies have been carried out on the ashes obtained directly from the industries to study Pozzolanic activity and their suitability as binders, partially replacing cement ${ }^{(6)}$. But these ashes are produced under uncontrolled and non uniform burning conditions with temperatures rising above $1000{ }^{\circ} \mathrm{C}$ resulting in the crystallization of the matter ${ }^{(4)}$. Present study was carried out on SCBA obtained directly from the Sudanese sugar companies.

Sugarcane production in Sudan is over $(700,000)$ tons/year leaving more than 70,000 tons of SCBA that was obtained by non uniform burning of sugarcane Bagasse. Pozzolanic and cementitious behavior of SCBA was evaluated by investigating the hydration reaction and strength development of SCBA - cement 
blended concrete ${ }^{(8)}$. Sugar Bagasse samples were collected from Sinnar Sugar Company, Asalaia Sugar Company and Guneid Sugar Company.

Crystallization of minerals occurred at temperatures higher than $800{ }^{\circ} \mathrm{C}{ }^{(9)}$. It has been reported that at burning temperatures up to $700^{\circ} \mathrm{C}$ silica was in amorphous form and silica crystals grew with time of incineration ${ }^{(10)}$. The suitable burning condition was identified as $800^{\circ} \mathrm{C}$ for 3 hours. At this condition brownish white color indicated complete burning, and amorphous nature of the ash was ascertained by X-ray diffraction analysis. SCBA so formed was not fine enough to be blended with cement; therefore to achieve fineness comparable to OPC, the ash obtained after burning was grounded in a ball mill and subsequently screened through $63 \mu$ sieve. Tables (4) \& (5) show the chemical and physical properties of the SCBA in comparison with $\mathrm{OPC}^{4}$.

\section{MATERIALS AND METHODS}

\subsection{Cement and aggregate:}

Ordinary Portland cement (OPC) produced from Atbara Cement Company was used and standard fine and coarse aggregate conforming to British Standards BS 882 grading zone M for coarse \& fine Aggregates were used for the preparation of concrete specimens.

Locally available free of debris sand is used as fine aggregate. The sand particles should also pack to give minimum void ratio, higher voids content leads to requirement of more mixing water. Those fractions from $4.75 \mathrm{~mm}$ to $150 \mathrm{mic}$ on are termed as fine aggregate or sand.

The size of coarse aggregate used was ranged between $14 \mathrm{~mm}$ as maximum and $2.36 \mathrm{~mm}$ as minimum, and are tested as BS 882 grading zone M for coarse Aggregates and the results are within the permissible limit.

\subsection{Sugar Cane Bagasse:}

Sugar Bagasse for this study was brought from Sudanese Sugar Company (Three samples were brought from Asalaia, Sinnar, and Guneid Sugar companies). The samples were grounded and sieved to grain size of less than $63 \mu \mathrm{m}$.

\section{Preparation of the Specimens:}

Concrete cubes of size 150x150x150mm, were prepared and cured using Sugarcane bagasse blended OPC cement. The OPC was replaced with 10, 20, and 30\% SCBA Table (2). The notations to identify the different samples of Sugarcane bagasse, used in the experimental work, were represented in Table (1).

Table (1) Notations to identify the different samples of SCBA used in the experimental work.

\begin{tabular}{|l|c|}
\hline Location of the Sample & Identified notation \\
\hline OPC & S1 \\
\hline Sinnar Sugar Company' Bagasse Ash & S2 \\
\hline Asalaia Sugar Company' Bagasse Ash & S3 \\
\hline Guneid Sugar Company' Bagasse Ash & S4 \\
\hline
\end{tabular}

\section{MIX DESIGN METHOD}

The mix design adopted in this investigation followed a method suggested by Cabrera based on a mix of maximum packing of Cement and sand particles strength and minimum porosity which has a cement : sand: coarse aggregates ratio of 1:2.33:3.5 Table (2)

This is the mix used as a control in the laboratories of concrete materials. The compositions of the different mixes used in the Investigation are given in Table (2).

The samples were incorporated in the mixes at 30\%, 20\%, and 10\% replacement levels, the mixes (OPC/SCBA) were made with the same W/C ratio of 0.55 as the OPC mix to observe the effect of the SCBA materials on the workability and strength.

Changes in Concrete properties investigated were then related to:

1. Varying the percentage of replacement of the OPC with others samples of Sugarcane Bagasse materials proportions $(10 \%, 20 \%$, and $30 \%)$.

2. Different types of Sugarcane Bagasse.

Table (2) concrete mix proportions (by weight)

\begin{tabular}{|l|l|l|l|l|l|}
\hline Mix & OPC & Sugarcane Bagasse $\left(\mathbf{S}_{\mathbf{i}}\right)$ & Sand & Gravel & water \\
\hline $\mathrm{OPC}$ & 1 & 0 & 2.33 & 3.5 & 0.55 \\
\hline $\mathrm{OPC} / \mathrm{S}_{\mathrm{i}}$ & 0.9 & 0.1 & 2.33 & 3.5 & 0.55 \\
\hline $\mathrm{OPC} / \mathrm{S}_{\mathrm{i}}$ & 0.8 & 0.2 & 2.33 & 3.5 & 0.55 \\
\hline $\mathrm{OPC} / \mathrm{S}_{\mathrm{i}}$ & 0.7 & 0.3 & 2.33 & 3.5 & 0.55 \\
\hline
\end{tabular}

Where $\mathrm{S}_{\mathrm{i}}$ represent $\mathrm{S} 2, \mathrm{~S} 3 \& \mathrm{~S} 4$ 


\section{MIXING AND CASTING}

The fresh concrete was mixed using flow pan mixer of $150 \mathrm{Kg}$ capacity till uniform through consistency was achieved, prior to the mixing; the materials were spread in layers in the bottom of the pan, coarse aggregate first, followed by cement and finally the fine aggregate. The constituents of the mixes were mixed dry for one minute in order to homogenize the batched mix; subsequently water was added and mixed for a further three minutes. The concrete was cast into the moulds in three layers, and 36 blows were given to each layer, using $16 \mathrm{~mm}$ diameter bar, to remove any entrapped air. For each mix the required numbers of cubes (total of 150 cubes) were casted. The moulds were covered by sacking for 24 hours at room temperature. The specimens were de-molded after at least 24 hours and immersed into the curing tank ${ }^{(6)}$.

Before the molding of the samples specimens workability tests were done to observe the effect of Sugarcane Bagasse on fresh concrete properties. The workability tests adopted for this investigation were the Slump test and compacting factor test. The results of the Slump and compacting factor tests for the various mixes were listed in Table (5) below.

Compressive strength was conducted at the age of 3, 7, 14, 28, and 90 days. The results were listed in Table (6)

V. PRESENTATION OF RESULTS

Table (3) chemical properties of OPC and SCBA

\begin{tabular}{|l|l|l|l|l|l|l|l|l|}
\hline \multirow{2}{*}{ Material } & \multicolumn{6}{|l|}{ Chemical composition (\%) } \\
\cline { 2 - 9 } & $\mathrm{SiO}_{2}$ & $\mathrm{Al}_{2} \mathrm{O}_{3}$ & $\mathrm{Fe}_{2} \mathrm{O}_{3}$ & $\mathrm{CaO}$ & $\mathrm{MgO}$ & $\mathrm{SO}_{3}$ & $\mathrm{~K}_{2} \mathrm{O}$ & LOI \\
\hline OPC(S1) & 21.26 & 5.1 & 2.59 & 64.96 & 2.02 & 1.8 & 0.3 & - \\
\hline $\mathrm{S} 2$ & 49.6 & 6.3 & 10.6 & 9.1 & 4.2 & 0.16 & 1.82 & 10.4 \\
\hline S3 & 38.5 & 5.9 & 8.8 & 4.9 & 4.6 & - & - & 10.8 \\
\hline S4 & 56.7 & 6.81 & 15.52 & 9.30 & 4.5 & - & - & 6.4 \\
\hline
\end{tabular}

Table (4) physical properties of OPC and SCBA

\begin{tabular}{|l|l|l|l|}
\hline \multirow{2}{*}{ material } & Density & Blaine area & Particle size \\
\cline { 2 - 4 } & $\left(\mathrm{g} / \mathrm{cm}^{3}\right)$ & $\left(\mathrm{cm}^{2} / \mathrm{g}\right)$ & $(\mu \mathrm{m})$ \\
\hline OPC $(\mathrm{S} 1)$ & 3.15 & 350 & $21-26$ \\
\hline S2 & 3.02 & 300 & $25-34$ \\
\hline S3 & 2.87 & 270 & $25-34$ \\
\hline S4 & 3.01 & 295 & $25-34$ \\
\hline
\end{tabular}

Table (5) Slump tests and compacting factor tests results

\begin{tabular}{|c|c|c|c|c|}
\hline Sample No. & Pozzolana & Cement & Slump (mm) & Compacting factor \\
\hline OPC (S1) & 0 & 100 & $22 \pm 2$ & 1.05 \\
\hline \multirow{3}{*}{ S2 } & 10 & 90 & $18 \pm 2$ & 1.10 \\
\cline { 2 - 5 } & 20 & 80 & $14 \pm 2$ & 1.13 \\
\cline { 2 - 5 } & 30 & 70 & $12 \pm 2$ & 1.15 \\
\hline \multirow{3}{*}{ S3 } & 10 & 90 & $17 \pm 2$ & 1.11 \\
\cline { 2 - 5 } & 20 & 80 & $13 \pm 2$ & 1.13 \\
\cline { 2 - 5 } & 30 & 70 & $11 \pm 2$ & 1.18 \\
\cline { 2 - 5 } & 10 & 90 & $17 \pm 2$ & 1.12 \\
\cline { 2 - 5 } & 20 & 80 & $14 \pm 2$ & 1.15 \\
\hline \multirow{3}{*}{ S4 } & 30 & 70 & $12 \pm 2$ & 1.20 \\
\hline
\end{tabular}

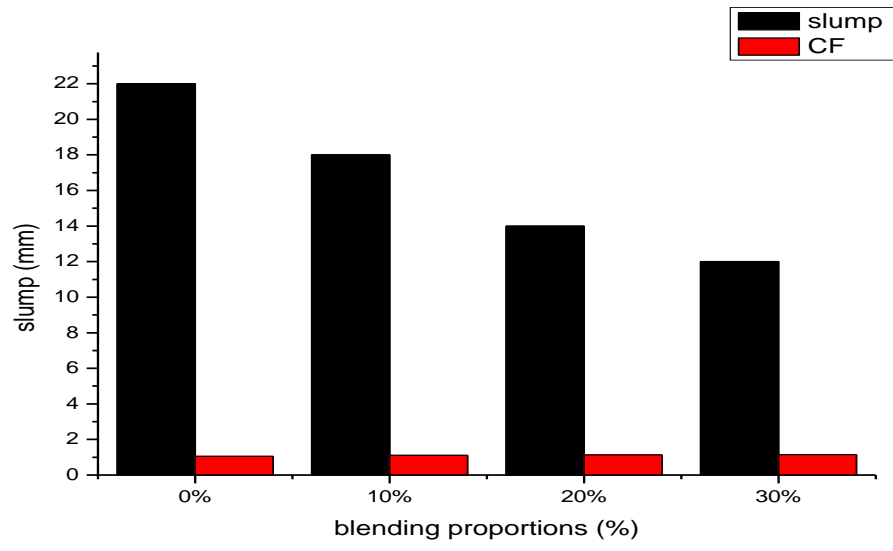

Figure (1) The effect of (S2) Cement replacement on workability 


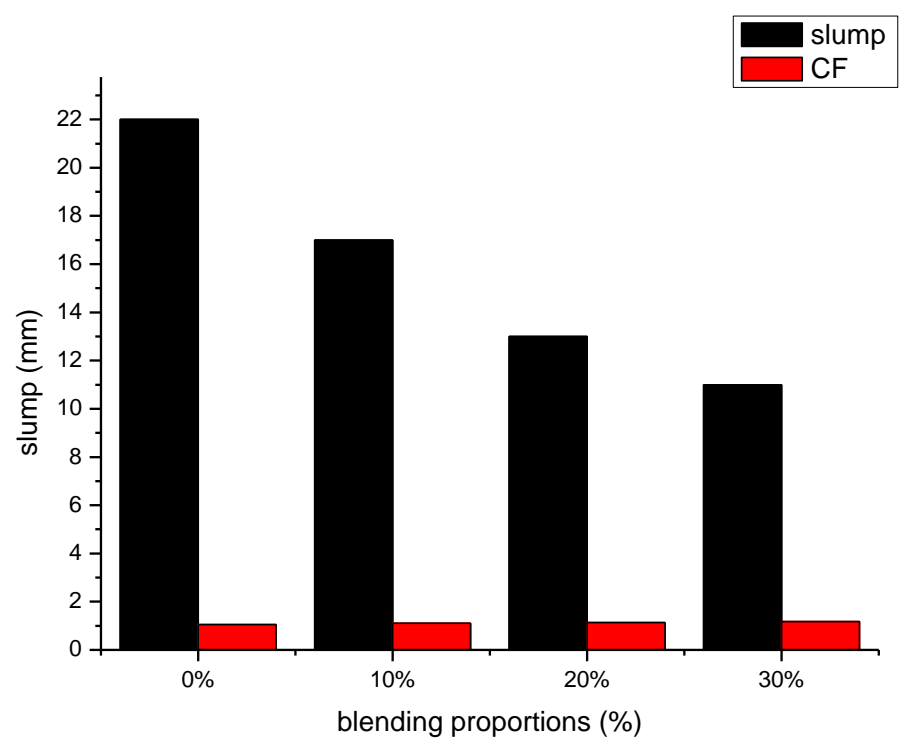

Figure (2) The effect of (S3) Cement replacement on workability

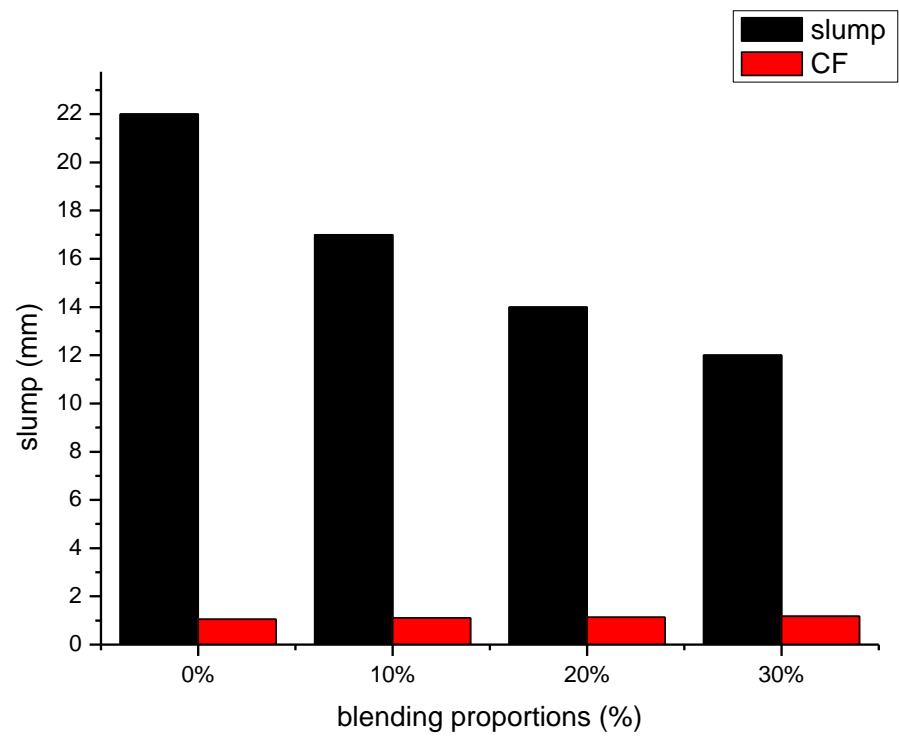

Figure (3) The effect of (S4) Cement replacement on workability.

Table (6): Strength activity development of blended concrete at 3, 7, 14, 28 and 90 days.

\begin{tabular}{|c|c|c|c|c|c|c|c|}
\hline \multirow[t]{2}{*}{ Sample No. } & \multicolumn{2}{|c|}{ Blending \% } & \multicolumn{5}{|c|}{ Compressive strength $\left(\mathrm{N} / \mathrm{mm}^{2}\right)$} \\
\hline & & & 3 days & 7 days & 14 days & 28 days & 90 days \\
\hline OPC (S1) & 0 & 100 & 22 & 28 & 32 & 35 & 35.5 \\
\hline \multirow[t]{3}{*}{ S2 } & 10 & 90 & 17 & 22 & 25 & 28.5 & 30 \\
\hline & 20 & 80 & 14 & 17 & 23 & 24 & 25.5 \\
\hline & 30 & 70 & 12 & 14 & 18 & 22 & 24 \\
\hline \multirow[t]{3}{*}{ S3 } & 10 & 90 & 17 & 21 & 24.5 & 27.5 & 30 \\
\hline & 20 & 80 & 13 & 16 & 22 & 25 & 26 \\
\hline & 30 & 70 & 12 & 15.5 & 19.5 & 23 & 24 \\
\hline \multirow[t]{3}{*}{ S4 } & 10 & 90 & 16 & 21 & 27 & 30 & 34 \\
\hline & 20 & 80 & 14 & 18 & 22.5 & 26 & 27 \\
\hline & 30 & 70 & 12 & 14.5 & 19.5 & 23.5 & 26.5 \\
\hline
\end{tabular}




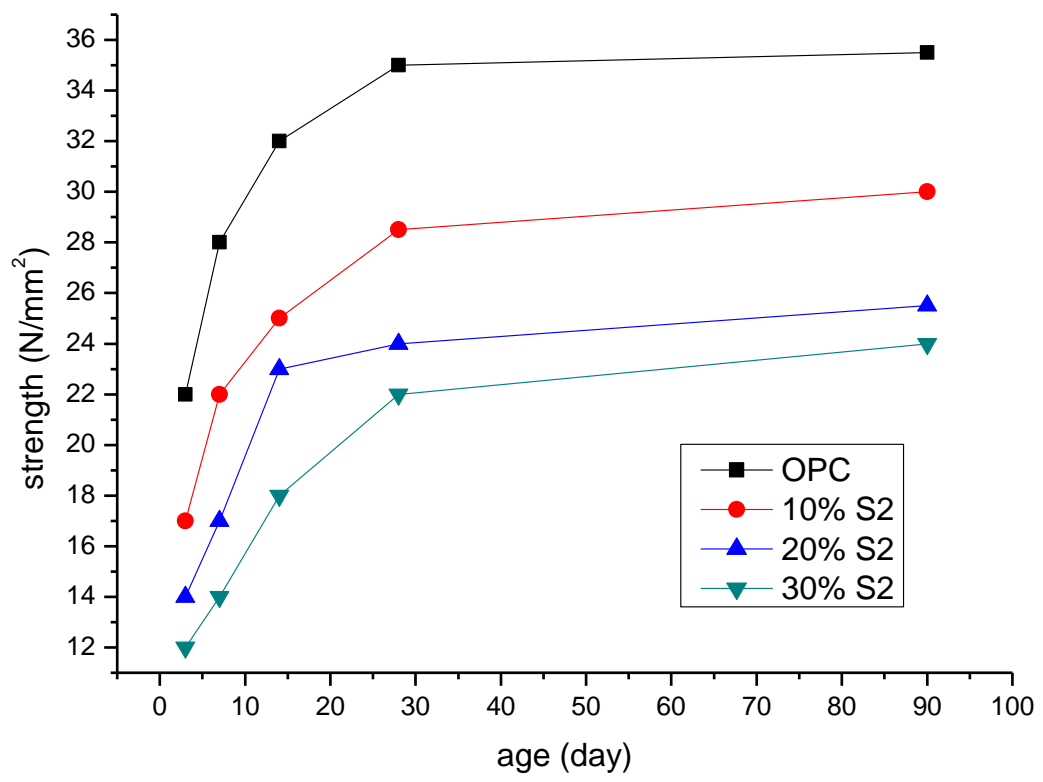

Figure (4) Strength development throughout the ages of S2 Sample replacement proportions compared with OPC.

$$
\begin{aligned}
& f^{\prime}=0.1085 d+27.418 \\
& f^{\prime}=0.1124 \mathrm{~d}+21.307 \\
& f^{\prime}=0.100 \mathrm{~d}+17.86 \text {. } \\
& f^{\prime}=0.1187 \mathrm{~d}+14.629 \text {. } \\
& \text {...(1). For OPC }\left(\mathrm{R}^{2}=0.303\right) \\
& \text {..(2). For } 10 \% \mathrm{~S} 2\left(\mathrm{R}^{2}=0.456\right) \\
& \text { (3). For } 20 \% \mathrm{~S} 2\left(\mathrm{R}^{2}=0.363\right) \\
& \text { (4). For } 30 \% \mathrm{~S} 2\left(\mathrm{R}^{2}=0.589\right)
\end{aligned}
$$

Where: $f^{\prime}$ is the strength in $\mathrm{N} / \mathrm{mm}^{2}$ and $\mathrm{d}$ is the age in days

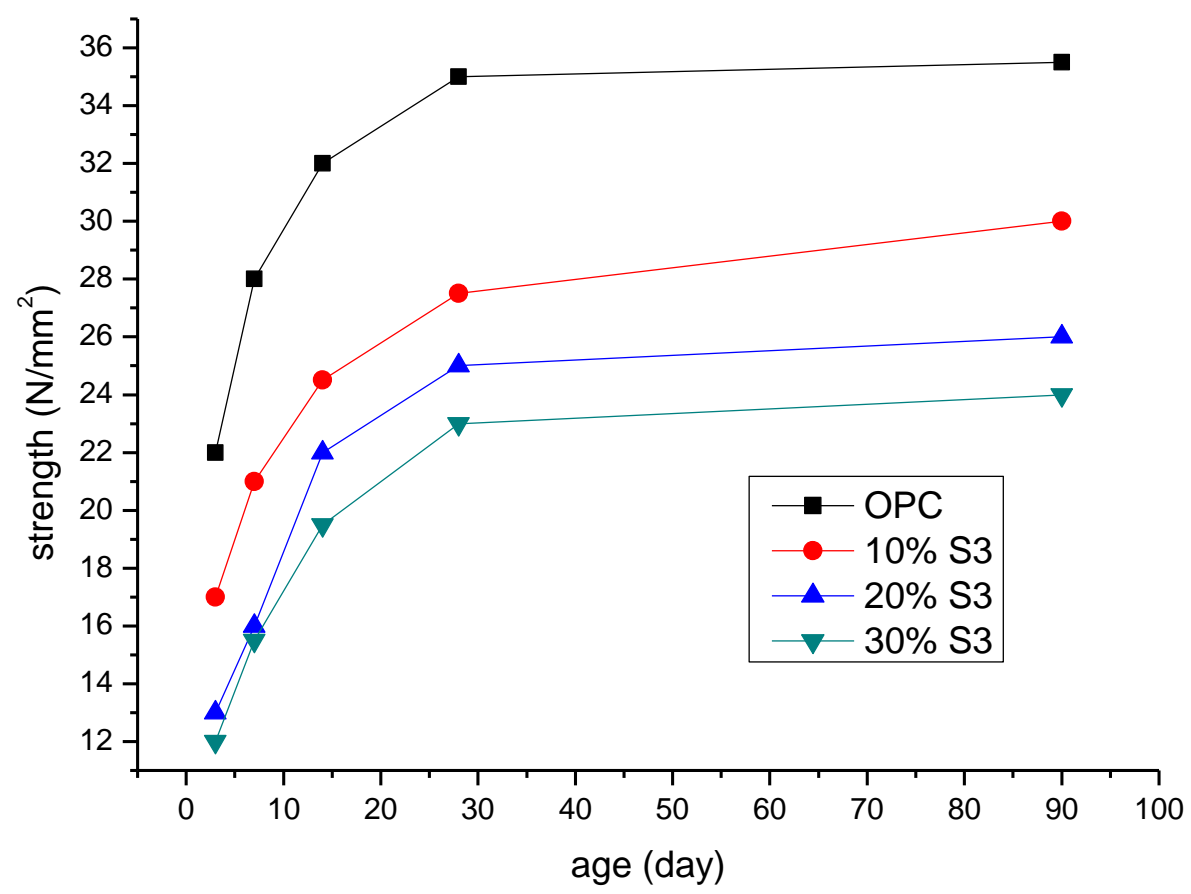

Figure (5) Strength development throughout the ages of S3 Sample replacement proportions compared with OPC. 
$f^{\prime}=0.1085 \mathrm{~d}+27.418$

..(1). For OPC $\left(\mathrm{R}^{2}=0.303\right)$

$f^{\prime}=0.1181 \mathrm{~d}+20.646$

(5). For $10 \% \mathrm{~S} 3\left(\mathrm{R}^{2}=0.558\right)$

$f^{\prime}=0.118 \mathrm{~d}+17.05$

..(6). For $20 \% \mathrm{~S} 3\left(\mathrm{R}^{2}=0.400\right)$

$f^{\prime}=0.1081 \mathrm{~d}+15.73$

(7). For $30 \% \mathrm{~S} 3\left(\mathrm{R}^{2}=0.444\right)$

Where: $f^{\prime}$ is the strength in $\mathrm{N} / \mathrm{mm}^{2}$ and $\mathrm{d}$ is the age in days

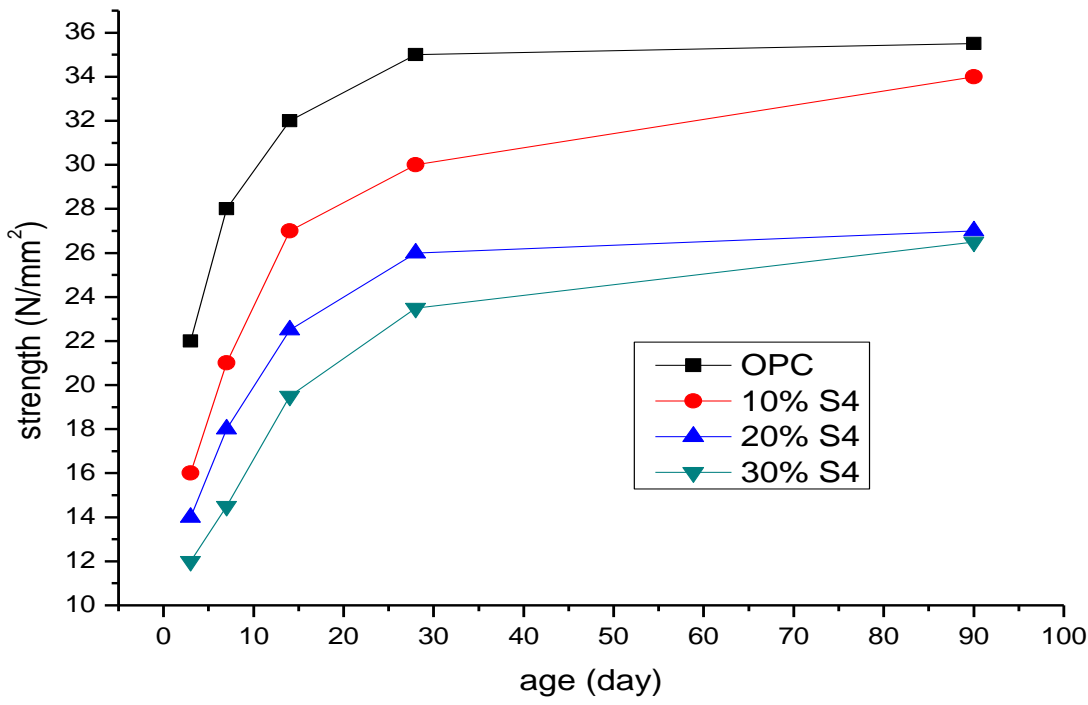

Figure (6)Strength development throughout the ages of S4 Sample replacement proportions compared with OPC.

$$
\begin{aligned}
& f^{\prime}=0.1085 \mathrm{~d}+27.418 \ldots \ldots \ldots \ldots \ldots \ldots \ldots \ldots \ldots \ldots \ldots(1) . \text { For OPC }\left(\mathrm{R}^{2}=0.303\right) \\
& f^{\prime}=0.1641 \mathrm{~d}+20.939 \ldots \ldots \ldots \ldots \ldots \ldots . .(8) . \text { For } 10 \% \mathrm{~S} 4\left(\mathrm{R}^{2}=0.56\right) \\
& f^{\prime}=0.1152 \mathrm{~d}+18.229 \ldots \ldots \ldots \ldots \ldots \ldots(9) . \text { For } 20 \% \mathrm{~S} 4\left(\mathrm{R}^{2}=0.419\right) \\
& f^{\prime}=0.1424 d+15.155 \ldots \ldots \ldots \ldots \ldots \ldots .(10) \text {. For } 30 \% \mathrm{~S} 4\left(\mathrm{R}^{2}=0.614\right)
\end{aligned}
$$

Where: $f^{\prime}$ is the strength in $\mathrm{N} / \mathrm{mm}^{2}$ and

$\mathrm{d}$ is the age in days

\section{DISCUSSION OF THE TESTS RESULTS}

\subsection{Physical and Chemical Properties:}

As shown in Table (4) \& (5), SCBA has low density and lower surface area (Blaine surface area) as compared to OPC.

Table (7)Comparison between chemical compositions of SCBA and and PFA according to ASTM- C-618 classification.

\begin{tabular}{|l|l|l|l|l|l|}
\hline Oxide & $\mathbf{S 2}(\boldsymbol{\%})$ & $\mathbf{S 3}(\boldsymbol{\%})$ & $\mathbf{S 4}(\boldsymbol{\%})$ & Calss F fly ash (\%) & Calss C fly ash (\%) \\
\hline $\mathrm{SiO}_{2}$ & 49.6 & 38.5 & 56.7 & $40-63$ & $32-42$ \\
\hline $\mathrm{Al}_{2} \mathrm{O}_{3}$ & 6.3 & 5.9 & 6.81 & $17-28$ & $15-20$ \\
\hline $\mathrm{Fe}_{2} \mathrm{O}_{3}$ & 10.6 & 8.8 & 15.52 & $3-12$ & $5-7$ \\
\hline $\mathrm{MgO}$ & 4.2 & 4.6 & 4.5 & $0.6-2$ & $4.1-6.1$ \\
\hline $\mathrm{CaO}$ & 9.1 & 4.9 & 9.3 & $2-8$ & $15-35$ \\
\hline $\mathrm{LOI}$ & 10.4 & 10.8 & 6.4 & $0-5$ & $0-0.5$ \\
\hline
\end{tabular}

The combined chemical composition; $\mathrm{SiO}_{2},+\mathrm{Al}_{2} \mathrm{O}_{3}+\mathrm{Fe}_{2} \mathrm{O}_{3}>70 \%$ (class $\mathrm{F}$ ) for sample $\mathrm{S} 4$ and $>50 \%$ (class $\mathrm{C}$ ) for $\mathrm{S} 2 \& \mathrm{~S} 3$ and $\mathrm{CaO}<10 \%$ testified the Pozzolanic and cementitious nature of SCBA as per ASTM C-618-03 specifications.

\subsection{Workability tests discussion:}

The workability tests results indicated that addition of SCBA reduced the workability; however this is within limits as specified in ASTM $C^{(5)}$. It could have been caused due to the adsorption of water at the surface of SCBA. The higher the proportion of SCBA, the higher was the adsorption of water and hence lower amount of water reduced the workability, further. Decrease in flow values can be attributed to the higher specific surface 
area of SCBA that required more water to wet the surface as compared to the OPC specimen also the high percentage of LOI may affect the degree of water absorption and in turn affect the workability.

\subsection{Compressive Strength Development:}

Results of compressive strength test conducted on cubes specimens represented graphically in Fig.(4, 5, \& 6) show that during experiment age of testing, all blended cubes specimens exhibited lower strength than OPC. This was due to the combined effect of relative fineness and the Pozzolanic activity of SCBA and also may be due to the existing of crystalline silica. According to Bui ${ }^{9}$ ) strengthening capability of a mineral admixture not only depends on the Pozzolanic reactivity, but also on the relative fineness of the filler material. At 90 day stage compressive strength for S4 10\% replacement was shown clear developing strength about $0.96 \%$ of OPC while the other samples (S2 \& S3) were shown 85\% strength development than OPC. Decrease in compressive strength values with increase in the substitution ratio indicated that filler effect was predominant only up to $10 \%$ ash substitution. The increase in compressive strength values in the S4 is due to the combined effect of both physical and chemical processes. Physical action was caused by the high specific surface area of SCBA $^{(6)}$ and chemical action was the Pozzolanic reaction between calcium hydroxide $(\mathrm{CH})$ and silica $\left(\mathrm{SiO}_{2}\right)$. Also the hydration of silica itself in the alkaline environment may have been responsible for increase in compressive strength. But hydration reaction in S2 and S3 specimen was slow; possible because of low reactivity of $\mathrm{SiO}_{2}$ and also, the reduction in $\mathrm{CaO}$ contents may have caused the reduction in ultimate strength development.

Results can be summarized as below:

\section{SUMMARY}

- Bagasse ash obtained produced a reactive material relatively free from carbon and other organic matter. SCBA with high specific surface area, high contents of amorphous silica and calcium oxide; fulfilled the principal requirements of a Pozzolanic material. A little amount of crystallization of silica present in ash, may have affected the degree of reactivity.

- Mechanical strength tests confirmed the actual behavior of the SCBA- blended concrete specimen as $10 \%$ substitution of OPC with SCBA, gave better strength results in comparison with OPC specimen.

\section{REFERENCES}

[1] Ajay Goyal, A.M. Anwar, Hattori kunio, OGATA Hidehiko. "Properties of Sugarcane Bagasse Ash and its potential as Cement - pozzolana Binder". Ain Shams University - Faculty of Engineering - Department of Structural Engineering. Dec. 2007

[2] Deepchand, K. Characteristics, "present use and potential of sugarcane tops and leaves, agricultural wastes", (1986) 15, 139-148.

[3] FAO: "production of agricultural commodities", FAO statistical year book 2005- 06, food and Agri. Org. of U. Nation, Italy, 2(III), 20061-4.

[4] Paya. J., et. Al., "Sugarcane Bagasse ash (SCBA): studies on its properties for reusing in concrete production", Jounal of chemical technology and Biotechnology, (2002)77,321-325.

[5] ASTM C618-(2005), "standard specification for Fly Ash or Raw or Natural pozzolana for Use as a mineral Admixture in Portland Cement Concrete", American Society for testing and materials.

[6] Khadija Qureshi, Inamullah Bhatti, Rafique KaziPhysical, Abdul Khalique Ansari."Physical and chemical Analysis of Activated Carbon Prepared from Sugarcane Bagasse and Use for Sugar Decolorisarion".international Journal of Natural Sciences and Engineering 1:3 2007.

[7] Baguant, K. : "properties of concrete with Bagasse ash as fine aggregate, in proc $5^{\text {th }}$ CANMET/ACI Intl. conf. on fly ash, silica fume, slag and natural pozzolanas in concrete", Ed by Malhotra VM, USA, ACI SP, (1995)153(18), 315337.

[8] Jayeshkumar R. Pitroda, Dr F S Umrigar, Vidhyanagar. "Evaluation of Modulus of Elasticity of Concrete with Partial Replacement of Cement by Thermal Industry Waste (Fly Ash) and Paper Industry Waste (Hypo Sludge)". International Journal of Engineering Science and Innovative Technology (IJESIT). January 2013.

[9] Gupta Arundeb, Mandal Saroj, Chosh Somnath. "Direct Comperssive Strength and Elastic Modulus of Recycled Aggregate Concrete". International Journal of Civil and Structural Engineering. November 2011.

[10] Patcharin Worathanakkul, Wisaroot Payubnop, and Akhapon Muangpet.. "Characterization for Post - treatment Effect of Bagasse Ash for Silica Extraction”.world Academy of Science, Engineering and technology.56 2009

[11] R. Srinivasan, K.Sathiya. "Experimental Study on Bagasse Ash in Concrete". International Journal for Service learning in Engineering. 2010.

[12] Mohamed Eljack Suliman and samah M. Fudl Almola. "The Use of Sugarecane Bagasse Ash as An Alternative Local Pozzolanic material". A scientific Journal of COMSATS - Science Vision. January 2011.

[13] Indian standard (IS: 1727- 1967). "Methods of test for Pozzolanic materials".

[14] Indian standard (IS: 4031- 1988). "Methods of physical test for hydraulic cement".

[15] Elsharif M. Ibrahiem, Salih A. M. Ahmed "Evaluation of Jebel Marra Volcanic Ash as Supplementary Cementitious Material for Use in Blended Cements”.IOSR Journal of Engineering (IOSRJEN). Vol. 04, Issue 03 (March. 2014). 